Gut, 1987, 28, 117-124

\title{
Liver and biliary
}

\section{Lysis of primary hepatic tumours by lymphokine activated killer cells}

\author{
KUE H HSIEH, SUYU SHU, CHUE S LEE, CHIEN T CHU, \\ CZAU S YANG AND KING J CHANG
}

From the Departments of Pediatrics, Surgery and Bacteriology, Taipei, Taiwan, Republic of China and Surgery Branch, National Cancer Institute, Bethesda, Maryland, USA

SUMMARY Lymphokine activated killer cell is a newly described lytic system against a variety of solid tumours and is distinct in several respects from the classic cytolytic $T$ cell and the natural killer systems. This study was conducted to evaluate the lytic activity of lymphokine activated killer cells against fresh autologous and allogeneic, as well as cultured hepatocellular carcinoma cells. Lymphokine activated killer cell was generated by incubating peripheral blood mononuclear cells with various concentrations of recombinant IL-2 (rIL-2, Cetus, USA) for various periods of time. A four hour ${ }^{51} \mathrm{Cr}$ release assay was used to measure cytotoxicity. The results show that fresh and cultured hepatocellular carcinoma cells were only slightly susceptible to natural killer cells. Normal hepatocytes were resistant to lymphokine activated killer-mediated lysis. Lymphokine activated killer cells could be generated from mononuclear cells of hepatocellular carcinoma patients and normal subjects with lytic activity against fresh autologous and allogeneic and cultured hepatocellular carcinoma cells, but lymphokine activated killer cells from the former was less efficient than that from the latter. It is concluded that the adoptive immunotherapy with combined rIL-2 and lymphokine activated killer may be worth trying in early cases of primary hepatocellular carcinoma.

Although rare in western countries, primary hepatocellular carcinoma ranks first as a cause of death from malignancy in Taiwan. ${ }^{1}$ Several studies strongly suggest that the high incidence of hepatitis B virus (HBV) infection in Chinese is causally related. ${ }^{23}$ With the availability of more sophisticated screening techniques, early diagnosis and resection of small hepatocellular carcinomas has become possible; however, the overall prognosis for hepatocellular carcinoma remains poor.

Despite extensive study of the immunopathogenesis of tumours in the past several decades, cancer immunotherapy in man is still without a demonstrably effective treatment. The generation of lymphoid cells cytolytic for fresh tumours in vivo or the adoptive transfer of cytolytic cells after specific in vitro sensitisation represent possible novel approaches to cancer therapy. Such procedures have, however, been hampered by the poor im-

Address for correspondence: Dr Kue-Hsiung Hsieh, Department of Pediatrics, National Taiwan University Hospital, 1 Chang-Te Street, Taipei, Taiwan 100, Republic of China.

Received for publication 22 April, 1986 munogenicity of most human tumours and the unavailability of suitable human tumour material for in vitro sensitisation.

Reports of the existence of a killer system against a variety of fresh solid tumours, the socalled lymphokine activated killer cells, recently have provided a promising new approach to the immunotherapy of tumours. In both murine and human systems, incubation of fresh lymphocytes with IL-2 resulted in the development of lytic activity. $^{4-7}$ Such lymphokine activated killer cells were able to kill a variety of natural killer resistant fresh autologous and allogeneic solid tumours. ${ }^{8}$ Subsequent studies demonstrated that lymphokine activated killer represents a cytotoxic system distinct from classic cytotoxic $\mathrm{T}$ cells and natural killer cells, viewed against a variety of characteristics-for example, lymphokine activated killer activity appeared as early as the third day after activation; ${ }^{8}$ only IL-2 (rIL-2) was required for generation ${ }^{9}$ io and no specific markers or antibodies reacting with its precursors have been identified (OKT3, OKT8, OKT11, OKM1, Leu-1 and Leu-7 have failed to identify the precursors). ${ }^{11}$ 
As the lytic activity of lymphokine activated killer against hepatocellular carcinoma cells has not been established in previously published reports, this study was conducted to examine the cytolytic effects of lymphokine activated killer from hepatocellular carcinoma erased patients and normal subjects on autologous and allogeneic fresh hepatocellular carcinoma cells and established hepatocellular carcinoma cell lines. Furthermore, lymphokine activated killer has been demonstrated to preferentially localise in the liver several days after intravenous infusion. ${ }^{12}$ Exploration of the use of lymphokine activated killer and rIL-2 in a clinical trial for the treatment of hepatocellular carcinoma cells is expected to be undertaken in the near future.

\section{Methods}

\section{PATIENTS}

Four patients with hepatocellular carcinoma and six healthy individuals were studied. The age of patients ranged from 39-51 years, with a mean of $46 \cdot 2$ years. All the patients were men and $\mathrm{HBs} A g-$ positive and had markedly increased $\alpha$-fetoprotein (4200 to over $35000 \mathrm{ng} / \mathrm{ml}$ ). The immunological function in terms of $T$ cell numbers and mitogenic responses were only slightly lower than normal. The six controls were men, aged from 29-42 years with a mean of 36.5 years, all were $\mathrm{HBsAg}$-negative and had normal $\alpha$-fetoprotein.

PREPARATION OF PERIPHERAL BLOOD

MONONUCLEAR CELLS

Mononuclear cells were isolated from normal individuals and cancer patients by the density gradient centrifugation of Boyüm, ${ }^{13}$ using Ficoll/ Hypaque. Mononuclear cells were washed three times with Hanks' balanced salt solution (HBSS, GIBCO, NY) and resuspended at a concentration of $1 \times 10^{6} \mathrm{cells} / \mathrm{ml}$ in complete culture medium $(\mathrm{CM}$, RPMI-1640 containing $100 \mathrm{U}$ penicillin/ml, $100 \mu \mathrm{g}$ streptomycin $/ \mathrm{ml}, 2 \mathrm{mM}$ L-glutamine $/ \mathrm{ml}$, fungisone $2.5 \mu \mathrm{g} / \mathrm{ml}$ and $10 \%$ heat-inactivated fetal calf serum). Blood from cancer patients was obtained before surgery and was used immediately.

\section{PREPARATION OF LYMPHOKINE ACTIVATED}

KILLER CELLS

Recombinant human interleukin 2 (rIL-2) was generously supplied by Cetus Corp. (Emeryville, CA, USA); its biological activity has been described previously. ${ }^{10}$ To determine the optimal condition for lymphokine activated killer generation, $2 \times 10^{6}$ mononuclear cells in $2 \mathrm{ml}$ culture medium containing $0,20,200,2000$, or $4000 \mathrm{U} / \mathrm{ml}$ of rIL-2 were placed in each well of 24-well culture plates (Nunc- lon, Denmark) and cultured in $37^{\circ} \mathrm{C}$, humidified, $5 \% \mathrm{CO}_{2}$ incubator for one to seven days; aliquots of the cells were harvested every day for cytotoxicity assay. Each time before testing, the lymphokine activated killer was washed three times with culture medium and the viabilities determined by trypan blue exclusion test.

\section{PREPARATION OF FRESH TUMOUR TARGET \\ CELLS}

The tumour target cells used to assay for lymphokine activated killer-mediated cytotoxic activity were prepared according to Grimm et al, ${ }^{8}$ with slight modification. Fresh resected hepatocellular carcinoma and hepatoblastoma were collected from surgery and processed immediately. Necrotic tumour and connective tissue were removed, and the remaining specimen was minced and stirred at room temperature in HBSS in a flask containing 5 $\mathrm{U} / \mathrm{ml}$ hyaluronidase, $2 \mathrm{mg} / \mathrm{ml}$ collagenase and 0.3 $\mathrm{mg} / \mathrm{ml}$ deoxyribonuclease (DNase). It usually took two to four hours to obtain a single cell suspension. The resulting cell suspension was then filtered through several layers of gauze to remove undigested material. The cells were then pelleted, washed, resuspended in HBSS, layered over Ficoll/ Hypaque gradient and centrifuged for 20 minutes at $800 \mathrm{~g}$. The cells on the interface cell layer were collected, washed, resuspended in culture medium and counted for viability by trypan blue exclusion. An aliquot was sent for cytologic analysis to determine the percentage of tumour cells; the rest was used either immediately or cryopresered in $90 \%$ human $\mathrm{AB}$ serum plus $10 \%$ dimethyl sulphoxide at a concentration of $2 \times 10^{7}$ cells $/ \mathrm{ml}$. The thawed cells were passed again through Ficoll/Hypaque before use to remove dead cells. In the final cell suspensions used for cytotoxicity study, the purity (tumour cells) was around $65 \%$ and the viability was over $75 \%$.

PREPARATION OF NORMAL LIVER CELLS

Normal liver tissues were obtained during abdominal surgery for diseases other than liver. The hapatocyte suspensions were prepared using the same method for tumours.

\section{CULTURED TUMOUR TARGETS}

Two human hepatocellular carcinoma cell lines, J5 and $\mathrm{J} 7$ whose characteristics have been described previously ${ }^{14}$ and $\mathrm{K} 562$, the natural killer-sensitive myeloid leukaemia cell line, were maintained in culture medium and split weekly at 1:100 dilution.

MEASUREMENT OF CYTOTOXICITY

A four hour ${ }^{51} \mathrm{Cr}$-release assay was used to measure 


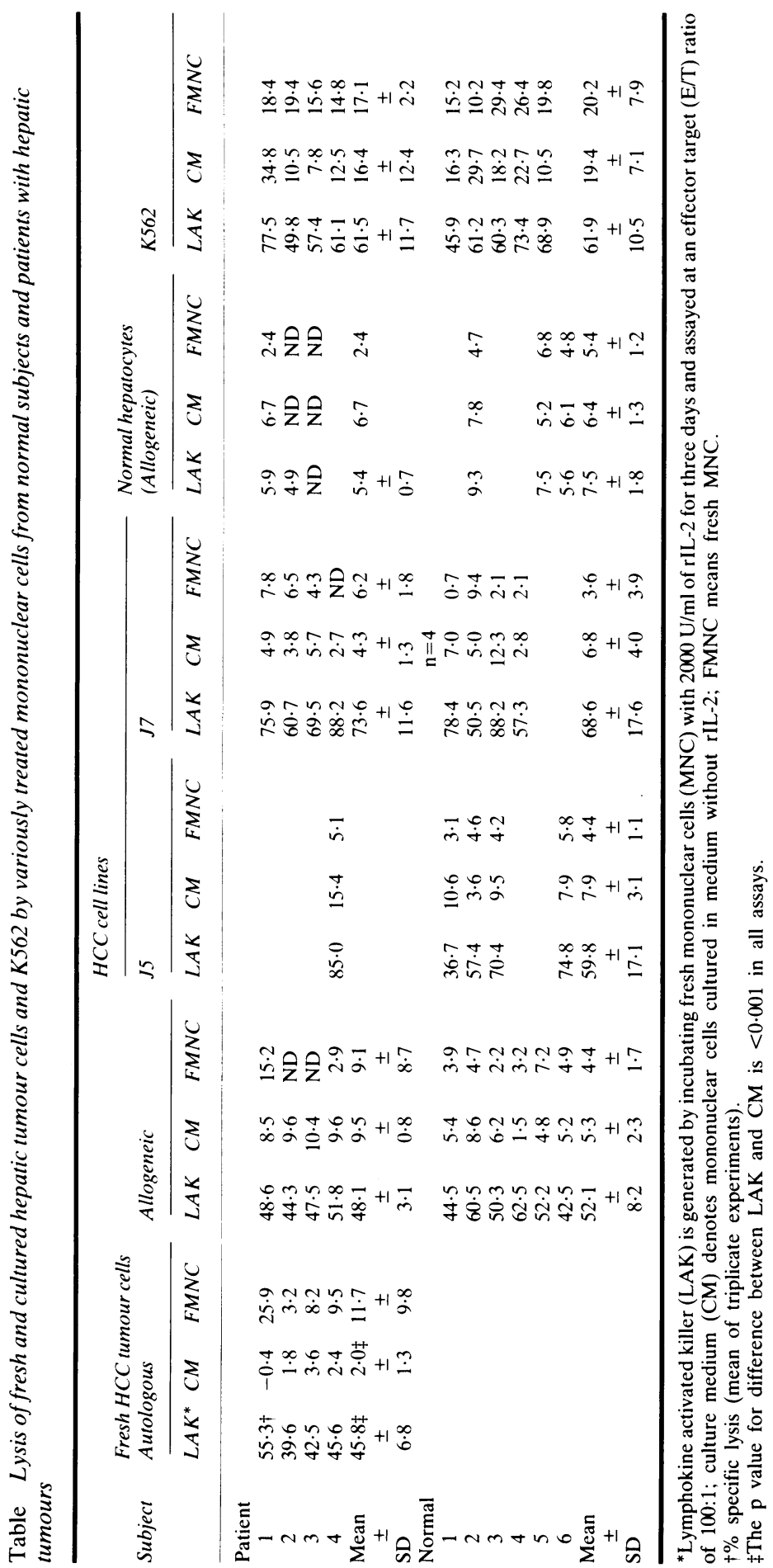


cytotoxicity of fresh and cultured tumour target cells. ${ }^{8}$ Ten million target cells in $0.5 \mathrm{ml}$ culture medium were labelled with $250 \mu \mathrm{Ci}$ of $\mathrm{Na}-{ }^{51} \mathrm{Cr} 04$ (NEN Corp; Boston, MA) for one hour. The cells were then washed three times with culture medium and added at $5 \times 10^{3}$ viable cells/well to various numbers of lymphokine activated killer or fresh effector mononuclear cells in round bottomed, 96 well microtitre plates (Lin-bro, Hamden, CT). The plates were centrifuged at $500 \mathrm{rpm}$ for three minutes and incubated for four hours in a $37^{\circ} \mathrm{C}$, humidified, $5 \% \mathrm{CO}_{2}$ incubator. The culture supernatants were harvested and the radioactivity was counted in a gamma counter. Maximal isotope release was produced by incubation of the targets with $0.1 \mathrm{~N}$ HCL. Spontaneous release was produced by incubation of targets with culture medium alone. The percentage of specific lysis was calculated by the formula: (experimental cpm-spontaneous cpm/maximal cpmspontaneous $\mathrm{cpm}) \times 100 \%$. All experiments were set up in triplicate and the mean was used for analysis (Table).
STATISTICAL ANALYSIS

Paired $t$ test was used to analyse the effect of rIL-2 on the generation of lymphokine activated killer. Wilcoxon's rank sum test was used to test the statistical difference in the lymphokine activated killer activity between patients and normal subjects.

\section{Results}

The data shown in the Table are the results of cytotoxicity assay (expressed as \% lysis) obtained at an effector/target ratio of $100: 1$, and lymphokine activated killer was generated with $2000 \mathrm{U} / \mathrm{ml}$ of rIL-2. The lymphokine activated killer from hepatocellular carcinoma patients could lyse J5, J7 and K562 cell lines as efficiently as those from normal subjects. The $\mathrm{J} 5$ and $\mathrm{J} 7$ were rather resistant to natural killer activity contained in fresh mononuclear cells. Furthermore, lymphokine activated killer always killed K562 to a much greater degree than did the fresh mononuclear cells.

The kinetics of lymphokine activated killer gen-

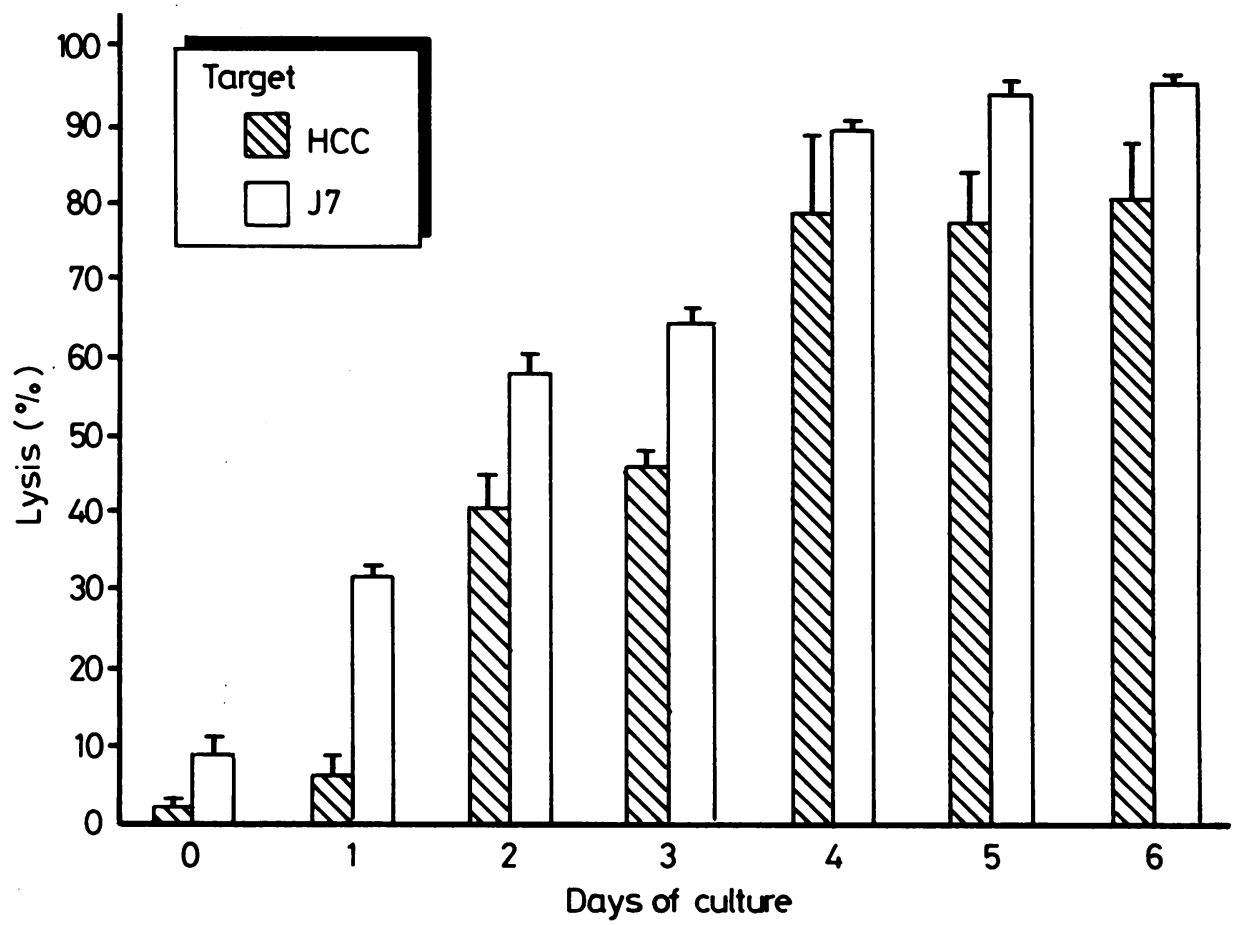

Fig. 1 Kinetics of lymphokine activated killer (LAK) generation. Mononuclear cells (MNC) from one patient were cultivated in the presence of 2,000 $\mathrm{U} / \mathrm{ml}$ of $\mathrm{rIL}-2$ for 7 days. Aliquots of cells were removed for testing lytic activity against fresh autologous and cultured hepatocellular carcinoma (HCC) cells. The lytic activity was evident from day two through day six. 
eration is shown in Figure 1. As the fresh mononuclear cells from both normal individuals and hepatocellular carcinoma patients could not lyse hepatocellular carcinoma cells to a significant degree (Table), the kinetics of lymphokine activated killer development was studied. Mononuclear cells were cultured in the presence of $2000 \mathrm{U} / \mathrm{ml}$ of rIL-2 and the lysis of $\mathrm{J} 7$ and cryopreserved hepatocellular carcinoma tumour cells was measured from day 1 through day 7 at an effector target ratio of 50:1. No lysis could be detected before day two; however, lytic activity was evident from day two through day six.

Lysis of fresh autologous hepatocellular carcinoma cells by lymphokine activated killer is shown in Figure 2 and the Table. Mononuclear cells from four hepatocellular carcinoma patients were obtained three days before scheduled operation and activated by various concentrations of rIL-2 for three days. The lytic activity of lymphokine activated killer and fresh mononuclear cells (obtained on the day of operation) against fresh autologous hepatocellular carcinoma tumour cells and $\mathrm{J} 7$ was measured simultaneously. One of those experiments (patient 1 ) is depicted in Figure 2. The mononuclear cells cultured in culture medium (without rIL-2) showed no lytic activity. The lytic activity appeared and paralleled the increase, however, in the amount of rIL-2 used during activation. Thus, the generation of lymphokine activated killer by rIL-2 is dose dependent. Moreover, at each concentration of rIL2 , the lymphokine activated killer usually lysed the cultured hepatocellular carcinoma cell line to a much greater extent than they lysed the fresh autologous hepatocellular carcinoma tumour cells. Finally, the lymphokine activated killer at higher effector target ratio (100:1, left panel, Fig. 2) killed hepatocellular carcinoma cells more efficiently than it did at lower effector target ratio (20:1, right panel).

It is important to note that, although lymphokine activated killer from both hepatocellular carcinoma patients and normal subjects could lyse autologous and allogeneic fresh hepatocellular carcinoma tumour cells and cultured hepatocellular carcinoma cell lines, lymphokine activated killer was unable to lyse normal hepatocytes, even when they were activated with a high concentration of rIL-2 (2000 $\mathrm{U} / \mathrm{ml}$ ) and assayed at the effector target ratio (100:1) (Table). Normal mononuclear cells were also resis-

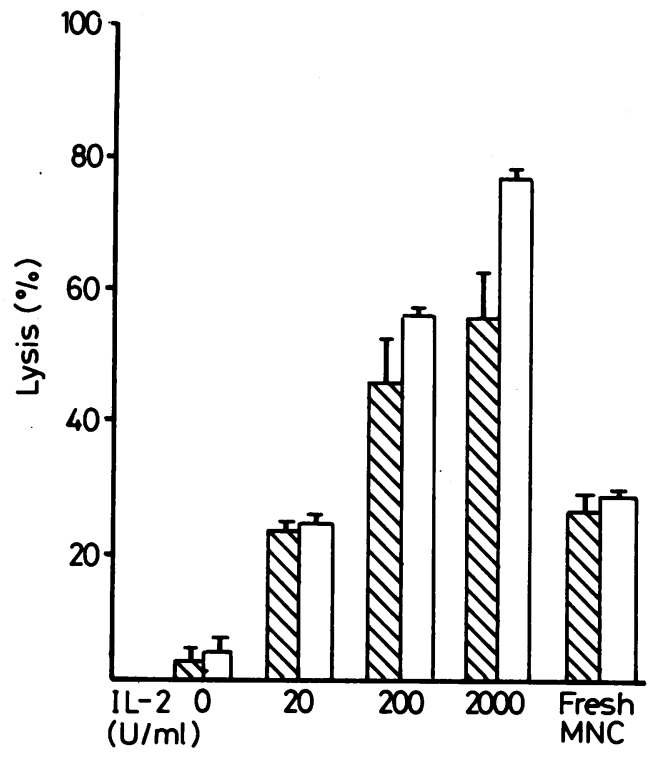

E :T ratio $\quad 100: 1$

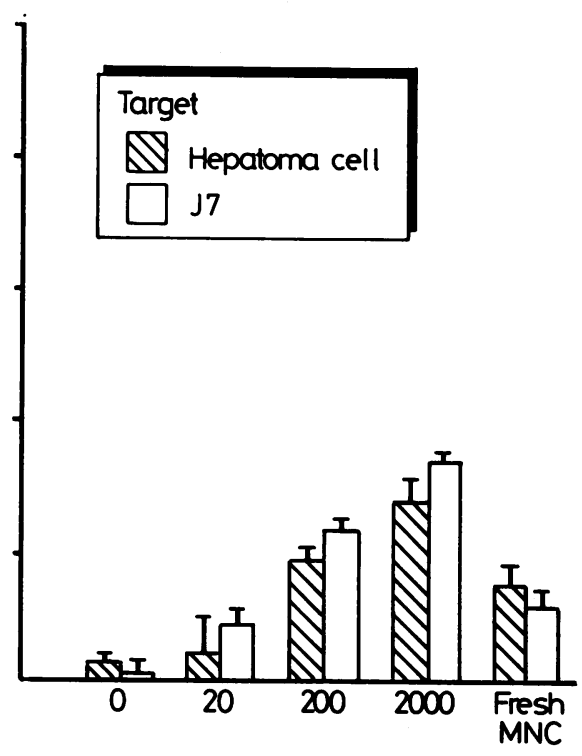

20: 1

Fig. 2 Magnitude of cytolytic activity of lymphokine activated killer (LAK) depends on both the dose of rIL-2 used in activation and the effector target $(E / T)$ ratio used in the assay. Mononuclear cells $(M N C)$ from one hepatocellular carcinoma $(\mathrm{HCC})$ patient were cultivated in the presence of various concentrations of rIL-2 for three days and the lytic activity against fresh and cultured hepatocellular carcinoma cells was tested at an effector target $(E / T)$ ratio of $100: 1$ and 20:1. The lymphokine activated killer activated with the highest rIL-2 concentration of 2,000 U/ml and tested at the effector target ratio of 100:1 showed the greatest cytolytic activity. 


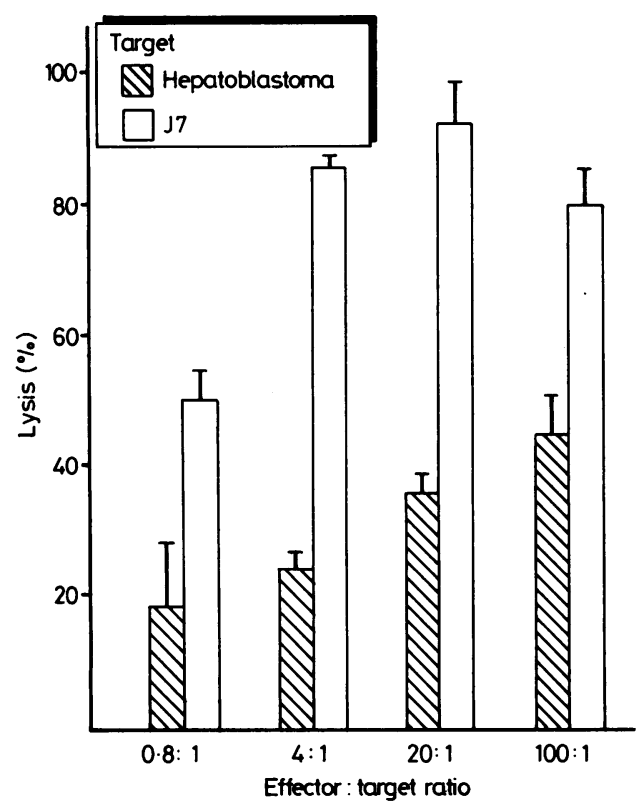

Fig. 3 Lymphokine activated killer ( $L A K)$ generated by three day's culture in $2000 \mathrm{U} / \mathrm{ml}$ of rIL-2 can also lyse fresh autologous hepatoblastoma, a primary hepatic tumor with complete different histology from hepatocellular carcinoma (HCC).

tant to lymphokine activated killer activity (data not shown).

The lymphokine activated killer activity of hepatocellular carcinoma patients was compared with that of normal subjects. The Table shows that at effector target ratio of 100:1 there was no difference in lymphokine activated killer activity between patients and normal subjects, no matter which kind of tumour cell was used as target. At a lower effector target ratio (20:1 or below) however, the lymphokine activated killer activity of patients was less efficient than that of normal subjects (data not shown).

The lymphokine activated killer phenomenon was also studied in an 8 month old boy with hepatoblastoma. As depicted in Figure 3, the lymphokine activated killer generated by $2000 \mathrm{U} / \mathrm{ml}$ of rIL-2 was able to lyse fresh autologous hepatoblastoma tumour cells. Thus, lymphokine activated killer can lyse primary tumours of the liver other than hepatocellular carcinoma.

\section{Discussion}

In animal models, several studies had reported successful treatment of syngeneic tumours by adop- tive transfer of lymphocytes specifically sensitised to tumour associated antigens. ${ }^{15} 16$ Such an approach, however, has been related to significant problems in extrapolating these results to man. Most tumour specific antigens are still ill defined; the immunogenicity, if present, is usually poor. No suitable human tumour material is available for in vivo and in vitro sensitisation and it is difficult to obtain large amounts of tumour specific lymphoid cells for repeated use even after the availability of rIL-2.

An alternative to the tumour specific reactive lymphoid cells is the non-specific killing of tumours by lymphoid cells activated using various ways and the lymphokine activated killer system first reported by Rosenberg et $a l^{4}$ appears to be the most attractive.

In murine models, local administration of IL-2 could inhibit tumour growth ${ }^{17}$ and intravenous infusion of lymphokine activated killer was able to decrease the numbers of established pulmonary melanoma. ${ }^{18}$ Moreover, simultaneous administration of lymphokine activated killer and rIL-2 have been reported to reduce the number and size of not only lung but also liver metastasis of sarcoma. ${ }^{19}$ In human models, intra- and perilesional injections of IL-2 could cause tumour necrosis. ${ }^{20}$ More recently, Rosenberg's group reported that while infusion of high dosage of only rIL-2 or lymphokine activated killer had no effect on tumour regression, ${ }^{21}$ the simultaneous administration of lymphokine activated killer and rIL-2 resulted in objective regression of tumour (more than $50 \%$ of volume) in 11 of 25 patients with metastatic cancer, and complete tumour regression in one which was sustained for more than 10 months after therapy. ${ }^{22}$

As mentioned before, hepatocellular carcinoma is the most commonly encountered cause of death from malignancy in Taiwan. ${ }^{1}$ Although a long list of tumours has been found to be susceptible to lymphokine activated killer, no information on hepatocellular carcinoma cells was available. As lymphokine activated killer has a preferential localisation in the liver after intravenous infusion,,$^{12}$ and has been proved able to reduce the metastasis of sarcoma to livers in mice, it would be very interesting to know whether lymphokine activated killer can also kill hepatocellular carcinoma cells in vitro, hoping to explore the possibility of treating hepatocellular carcinoma by lymphokine activated killer and rIL-2 in the future.

The results obtained in this study show that the lymphokine activated killer is able to lyse fresh and cultured hepatocellular carcinoma cells as well as fresh hepatoblastoma cells which were only slightly susceptible to natural killer activity (Table). In 
contrast, normal hepatocytes were resistant to lytic activity of lymphokine activated killer (Table). The generation of lymphokine activated killer was both time-dependent (Fig. 1) and dose (rIL-2)-dependent (Fig. 2). The lymphokine activated killer activity appeared 48 hours after activation by rIL-2 and persisted for at least six days. Moreover, the higher the concentration of rIL-2 used, the greater the lymphokine activated killer activity generated.

It is interesting to note that mononuclear cells from patients could be induced to generate lymphokine activated killer activity by rIL-2 as well as in normal subjects, especially when a high effector target ratio $(100: 1)$ was used in the cytotoxicity assay. At an effector target ratio of 20:1 or lower, however, the lytic activity of lymphokine activated killer of patients was weaker than that of normal subjects. Perhaps this indicates that the frequency of the lymphokine activated killer precursors, or the ability of lymphokine activated killer precursors to be activated by rIL-2, is reduced in hepatocellular carcinoma patients. All the data are consistent with those of Rosenberg's group,$^{23}$ but no hepatocellular carcinoma or hepatoblastoma was studied in their series.

In all experiments the lymphokine activated killer killed $\mathrm{K} 562$, the natural killer-sensitive myeloid leukemia cell line, to a much greater magnitude than did fresh mononuclear cells (Table). As natural killer activity had been reported to be augmented by IL-2, ${ }^{24} 25$ the enhanced killing of K562 by lymphoid cells activated by IL-2 may be the result of the combined effect of lymphokine activated killer and IL-2- enhanced natural killer activity. This supposition is supported by the finding recently reported by Itoh et $a l^{26}$ that Leu $11^{+}$large granular lymphocytes (a relatively reliable marker for natural killer cells in the human) contribute considerably to the generation of cytotoxic cells after IL-2 activation.

Though the reason why IL-2 can generate lymphokine activated killer, and the action mechanisms by which lymphokine activated killer lyses a variety of natural killer-resistant fresh solid tumours, are still unknown; because of its success in the treatment of established metastatic cancer in both rodents ${ }^{17-19}$. and man, ${ }^{22}$ especially its preferential localisation in the liver after intravenous infusion, ${ }^{12}$ the lymphokine activated killer system may provide a new approach to the immunotherapy of hepatic tumours after a large amount of IL-2 becomes available through the gene cloning technique. Actually, phase 1 clinical trials of lymphokine activated killer and rIL-2 in the treatment of hepatocellular carcinoma cells are already underway in this laboratory.

The authors express their great gratitude to Ms
Mei-Cheng Chiang and Hui-Lin Wu for their excellent technical help and to Ms Mei-Ching Yang for typing the manuscript. This study was supported by a grant from The National Science Council of The Republic of China, grant no NSC 74-0412B002-11.

\section{References}

1 Department of Health, Executive Yuan; Department of Health, Taiwan Provincial Government; Taipei City Health Bureau: General Health statistics Taiwan Provincial Government, 1977: 54-56.

2 Tong MT, Sun SC, Scheaffer BT. Hepatitis-associated antigen and hepatocellular carcinoma in Taiwan. Ann Intern Med 1975; 75: 687-9.

3 Beasley RP, Hwang LY, Lin C. Hepatocellular carcinoma and HBV: a prospective study of 22,707 men in Taiwan. Lancet 1981; 2: 1129-33.

4 Yron I, Wood Jr. TA, Spiess PJ, Rosenberg SA. In vitro growth of murine $\mathrm{T}$ cells. $\mathrm{V}$. The isolation and growth of lymphoid cells infiltrating syngeneic solid tumours. J Immunol 1980; 125: 238-45.

5 Lotze MT, Grimm EA, Mazumder A, Strausser JL, Rosenberg SA. In vitro growth of cytotoxic human lymphocytes. IV. Lysis of fresh and cultured autologous tumor by lymphocytes cultured in $\mathrm{T}$ cell growth factor. Cancer Res 1981; 41: 4420-5.

6 Teh HS, Yu M. Activation of nonspecific killer cells by interleukin 2-containing supernatants. J Immunol 1983; 131: $1827-33$.

7. Merluzzi VJ, Savage DM, Roland $\mathbf{M}$, Welte $\mathrm{K}$. Generation of nonspecific murine cytotoxic $\mathrm{T}$ cells in vitro by purified human interleukin 2. Cell Immunol 1984; 84: 74-84.

8 Grimm EA, Mazumder A, Zhang HI, Rosenberg SA. Lymphokine-activated killer cell phenomenon. Lysis of natural killer-resistant fresh solid tumour cells by interleukin 2-activated autologous human peripheral blood lymphocytes. $J$ Exp Med 1982; 155: 1823-41.

9 Grimm EA, Robb RJ, Roth JA, et al. Lymphokineactivated killer cell phenomenon. III. Evidence that IL-2 is sufficient for direct activation of peripheral blood lymphocytes into lymphokine-activated killer cells. J Exp Med 1983; 158: 1356-61.

10 Rosenberg SA, Grimm EA. McGrogan M. Biological activity of recombinant human interleukin 2 produced in Escherichia coli. Science 1984; 223: 1412-5.

11 Grimm EA, Ramsey KM, Mazumder A. Lymphokineactivated killer cell phenomenon. II. Precursor phenotype is serologically distinct from peripheral $T$ lymphocytes, memory cytotoxic thymus-derived lymphocytes, and natural killer cells. J Exp Med 1983; 157: 884-97.

12 Lotze MT, Line BR, Mathisen DJ, Rosenberg SA. The in vivo distribution of autologous human and murine lymphoid cells grown in T cell growth factor (TCGF). Implication for the adoptive immunotherapy of tumors. J Immunol 1980; 125: 1487-93.

13 Boyüm A. Isolation of mononuclear cells and granulo- 
cytes from human blood. J Clin Lab Invest 1968; 21 suppl 97: 77-89.

14 Chang K SS, Wang LC, Yang CS. Studies on human hepatocellular carcinoma cell lines. Karyotype, retrovirus replication, and cellular oncogenes. Proceedings of The Taipei Pre-congress Symposium of The Sixth International Congress of Virology, p17, Taipei Republic of China: The Chinese Society for Microbiology, 1984.

15 Cheever MA, Greenberg PD, Alexander F. Specific adoptive therapy of established leukemia with syngeneic lymphocytes sequentially immunized in vivo and in vitro and nonspecifically expanded by culture with interleukin 2. J Immunol 1981; 126: 1318-22.

16 Rosenberg SA, Terry TV. Generation of long-term T. lymphoid cell lines with specific cytotoxic reactivity for a syngeneic murine lymphoma. Adv Cancer Res 1977; 25: 323-88.

17 Forni G, Giovarelli M, Santoni A. Lymphokineactivated tumor inhibition in vivo. I. The local administration of interleukin 2 triggers nonreactive lymphocytes from tumor bearing mice to inhibit tumor growth. J Immunol 1985; 134: 1305-11.

18 Mazumder A, Rosenberg SA. Successful immunotherapy of natural killer-resistant established pulmonary melanoma metastases by the intravenous adoptive transfer of syngeneic lymphocytes activated in vitro by interleukin 2. J Exp Med 1984; 159: 495-507.

19 Mule JJ, Shu Suyu, Schwarz L, Rosenberg SA. Adoptive immunotherapy of established metastases with LAK cells and recombinant interleukin 2. Science 1984; 225: 1487-9.

20 Pizza G, Severini G, de Vinvi C, Corrado F. Tumor regression after intralesional injection of interleukin 2 (IL-2) in bladder cancer. Preliminary report. Int J Cancer 1984; 34: 359-67.

21 Lotze MT, Matory YL, Rosenberg SA et al. In vivo administration of purified human interleukin 2. II. Half life, immunologic effects, and expansion of peripheral lymphoid cells in vivo with recombinant IL-2. J Immunol 1985; 135: 2865-75.

22 Rosenberg SA, Lotze MT, Muul LM, et al. Observations of the systemic administration of autologous lymphokine-activated killer cells and recombinant interleukin-2 to patients with metastatic cancer. $N$ Engl J Med 1985; 313: 1485-92.

23 Grimm EA, Rosenberg SA. The human lymphokineactivated killer cell phenomenon, In Pick E, ed, Lymphokines New York: Academic Press, 1984; 9: 279-311.

24 Dennert G, Yogeeswaran G, Yamagata S. Cloned linee with natural killer activity. J Exp Med 1980; 153: 545-56.

25 Henney CS, Kuribayashi K, Kern DE, Gillis S. Interleukin-2 augments natural killer activity. Nature 1981; 291: 335-8.

26 Itoh K, Tilden AB, Kumagai K, Balch CM. Leu-11 + lymphocytes with natural killer (NK) activity are precursors of recombinant interleukin 2 (rIL-2) induced activated killer (AK) cells. J Immunol 1985; 134: 802-7. 